\title{
Pattern of Pulmonary Dysfunctions in Craniovertebral Junction Anomaly and Its Persistence after Rigid Occipitocervical Fixation
}

\author{
Shaam Bodeliwala' Vikas Nagar $^{1}$ Hukum Singh ${ }^{1}$ \\ Rajesh Ruttala ${ }^{3}$ Pankaj Kumar ${ }^{2, \odot}$ \\ ${ }^{1}$ Department of Neurosurgery, Govind Ballabh Pant Institute of \\ Postgraduate Medical Education and Research (GIPMER), \\ New Delhi, Delhi, India \\ ${ }^{2}$ Department of Neurosurgery, Dr. Ram Manohar Lohia Hospital and \\ Post Graduate Institute of Medical Education and Research, \\ New Delhi, Delhi, India \\ ${ }^{3}$ Department of Medicine, Maulana Azad Medical College, \\ New Delhi, Delhi, India
}

Daljit Singh ${ }^{1} \quad$ Anita Jagetia ${ }^{1}$ Sharad Pandey ${ }^{2}$

Indian J Neurosurg:2020;9:157-161

\begin{abstract}
Address for correspondence Pankaj Kumar, MS, MCh, Room No. 202, Academic Block 2nd floor, PGl Building, Atal Bihari Vajpayee Institute of Medical Sciences (ABVIMS) and Dr Ram Manohar Lohia hospital, Baba Kharak Singh Marg, Near Gurudwara Bangla Sahib,Connaught Place, New Delhi, Delhi 110001, India (e-mail: aditya.thewinner@gmail.com).
\end{abstract}

\section{Abstract}

Keywords

- craniovertebral junction anomalies

- rigid occipitocervical fixation

- pulmonary function test
Introduction Despite a significant advancement in operative techniques of occipitocervical fixation, there is a poor postoperative patient outcome. This can be attributed to restrictive lung pattern in craniovertebral junction anomalies (CVJAs) patients resulting from repeated trauma to cervicomedullary junction by the pincer action of the bony anomalies and compression of the brainstem. We evaluate the changes in pulmonary function tests (PFTs) following rigid occipitocervical fixation in CVJA.

Methods PFTs of 20 CVJA patients were measured pre and postoperatively using spirometry. Measurements included forced vital capacity (FVC), forced expiratory volume in one second (FEV1), maximum forced mid-expiratory flow rate (FEF25-75\%), and ratio of FEV1 and FVC (FEV1\%). The parameters were compared with the predicted normal values based on their age and sex. PFTs were repeated on the seventh postoperative day. McCormick grading was used to assess neurological function.

Results The values of PFTs in the preoperative period were significantly lower than predicted normal values. The mean values of FVC, FEV1, FEF25-75\% were 72, 68, and $71 \%$ of their mean predicted values, with FEV1\% in the range of 70 to $95 \%$ with a mean of $81.4 \%$. Postoperatively there was further significant reduction in the mean values of FVC, FEV1, FEF25-75\%, and FEV1\% compared with the preoperative values. There was neurological improvement in McCormick grades of patients postoperatively (from grade III and IV to grade II).

Conclusion A significant restrictive lung disease is present in patients of CVJA, even though not clinically apparent, and it persists in the early postoperative period. However, a long-term follow-up is required to assess whether pulmonary function parameters improve subsequently.
DOI https://doi.org/

10.1055/s-0040-1712064 ISSN 2277-954X. (c) 2020. Neurological Surgeons' Society of India.

This is an open access article published by Thieme under the terms of the Creative Commons Attribution-NonDerivative-NonCommercial-License, permitting copying and reproduction so long as the original work is given appropriate credit. Contents may not be used for commercial purposes, or adapted, remixed, transformed or built upon. (https://creativecommons.org/licenses/by-nc-nd/4.0/)

Thieme Medical and Scientific Publishers Pvt. Ltd., A-12, 2nd Floor, Sector 2, Noida-201301 UP, India 


\section{Introduction}

The craniovertebral junction (CVJ) is a transition site between mobile cranium and relatively rigid spinal column. It is also the site of the medullo-spinal junction. CVJ anomalies are defects of development, not necessarily congenital, and may not manifest at birth. The occipitocervical joint consists of the occiput, atlas, and axis and contributes to more than $50 \%$ of the rotation and flexion-extension of the head and neck. ${ }^{1} \mathrm{~A}$ wide variety of abnormalities affect the occipitocervical junction causing instability of joint, which finally leads to neural compression and craniospinal instability. ${ }^{2-8}$ Occipitocervical fixation has undergone significant evolution due to advances in operative and instrumentation techniques. C1-C2 screw fixation had biomechanically been demonstrated to be superior in providing immediate rigidity and eliminating the need for external immobilization when compared with other methods, leading to higher rates of fusion; the method was the "gold standard" for occipital fixation. ${ }^{9}$ But the specific anatomical constraints caused by congenital abnormalities, such as a high-riding transverse foramen, small or narrow pedicles of $\mathrm{C} 2$, and dysplasia of the C1 lateral mass, may preclude placement of the screws, ${ }^{10}$ and there was a risk of dural, neural, or vertebral artery injury from errant screw placement. ${ }^{10,11}$ Occipitocervical fixation procedure has evolved from simple autograft on-lay fusion techniques to sublaminar wiring techniques and, most recently, rigid occipital plating with screws connected via rods to atlantoaxial or subaxial screw fixation., ${ }^{3,9,12-17}$ The majority of occipitocervical lesions are anterior and anterolateral. Posterior surgical decompression remains invaluable for the treatment of these lesions (in select cases), as well as the posteriorly situated lesions.

Reduction surgery and internal fixation are chosen when positioning or traction alone is adequate for the realigning of the column, but irreducible deformities need additional decompressive surgery using an anterior/ transoral or posterior approach depending on the site of compression. ${ }^{7,18,19}$ Occipitoatlantoaxial instability due to rheumatoid arthritis (RA), trauma, neoplasms, dens dysplasia or os odontoideum, Down syndrome, ${ }^{3,5-8,12,18}$ and occasionally a prior failed attempt at $\mathrm{C} 1-\mathrm{C} 2$ fusion or a complex cervical deformity, ${ }^{13}$ are the commonest indications for occipitocervical fusions. Occipitocervical fixation is a challenging field in spinal surgery. Many authors report excellent results from occipitocervical fixation by using various internal fixation implants. The recent development of image guidance systems has increased the percentage of successful screw insertions and decreased risk of complications associated with screw malposition. ${ }^{20,21}$ According to meta-analysis, the rate of penetration of the pedicle cortex by an inserted screw without the use of navigation was almost $10 \%$, and with the use of spinal navigation, the rate of screw misplacement improved considerably. ${ }^{22}$ In one series, the combination of intraoperative computed tomography (CT) and neuronavigation provided the choice of suited lateral mass or pedicle. It improved the accuracy of screw placement and avoided the risk of dural, neural, or vertebral artery injury. The overall accuracy of screw placement was $98.1 \%$. No major complications occurred in any of the patients. As some pedicles of $\mathrm{C} 2$ were narrow, the C3 or C4 screw fixation could provide superior immediate postoperative stability. No patient was detected with the penetration of the occipital cortex by an inserted screw. Another advantage of this technique was rigid stability. Rigid stability increased osseous fusion rate. All the patients in the series got osseous fusion in the follow-up. Moreover, categorizing patients according to McCormick functional scale is useful to assess operative outcomes in preoperative period. The scale provides a practical means of comparing pre- and postoperative neurological condition. Eleven patients (92\%) were improved by at least one McCormick grade, whereas the grade did not change in one patient (8\%) in the series. ${ }^{22}$ Although the indications for simultaneous decompression and fixation in patients with basilar invagination associated with Chiari malformation are controversial, ${ }^{22}$ in a study, the authors found that rigid internal fixation of the occipitocervical complex was safe, effective, and technically possible for spine surgeons familiar with occipital bone anatomy and lateral mass fixation. In another study, the authors described a revised surgical technique with intraoperative CT navigation system for the treatment of craniocervical junction malformation associated with inappropriate excessive posterior fossa decompression. ${ }^{23}$

The patients of CVJ anomalies have impaired pulmonary functions. This often results in poor outcome despite good surgery. Respiratory dysfunctions in such anomalies occur probably due to compression of the brainstem, affecting the respiratory center and weakening the respiratory muscles. The respiratory dysfunctions associated with such anomalies are also considered to be the result of repeated trauma to cervicomedullary junction by the pincer action of the bony anomalies.

Though well known, the pattern of respiratory dysfunction, that is, obstructive, restrictive, or both have not been eloquently studied. The impairment of respiratory dysfunction is supposed to improve following rigid fixation yet prolonged impairment of respiratory dysfunction may persist in some patients in the postoperative period. This study was conducted with the aim to evaluate the changes in pulmonary function test (PFT) following surgery.

\section{Materials and Methods}

It was a prospective study conducted between February 2014 and October 2015 in our institution in the Department of Neurosurgery. Ethical clearance was taken from the Institutional Ethical Committee. This study included 20 patients with clinicoradiologic diagnosis of craniovertebral junction anomalies. Patients with the age group between 16 and 60 years with CVJ anomalies with fixed or mobile joint were included in the study.

The procedure was explained to the patient and information about the potential complications particularly about the risk of surgery was provided to them. Patients were evaluated before the procedure with PFT using spirometer super Spiro V 2.10 machine in the sitting position. After sufficient practice 
three satisfactory recordings were obtained for each subject and the best of the three was taken for analysis. Spirometric measurements include recording of forced vital capacity (FVC), forced expiratory volume in one second (FEV1), maximum forced mid-expiratory flow rate (FEF25-75\%), and ratio of FEV1 and FVC (FEV1\%)). The parameters were compared with the predicted normal values for these patients based on their age and sex. These predictive values were already displayed on spirometer machine. McCormick grading to assess neurological function was used. ${ }^{19}$ Rigid occipitocervical fixation was done using rod and screws. The patients were shifted to neurosurgery intensive care unit (ICU) after the operation and were extubated in ICU for 96 hours. Incentive spirometry and chest physiotherapy were started as soon as possible after extubation.

The operated patients were examined for neurological changes (McCormick grading) after using the fixation techniques. Pulmonary function study was done on the seventh postoperative day.

IBM SPSS statistical 19.0 (statistical product and service solutions) was used to analyze the data.

\section{Results}

Neck pain originating in suboccipital region and extending up toward vertex was most common complaint present in $80 \%$ of the cases. Syncope, vertigo, and altered level of consciousness were noted in $20 \%$ of the cases. Myelopathy was the commonest neurological deficit present in all patients. Chest expansion and breath holding time was reduced in $60 \%$ of the cases. Single breath count was decreased in $70 \%$ of the cases. Posterior column dysfunction was noted in $50 \%$ of the cases. Bladder incontinence was present in $40 \%$ of the cases. Loss of gag reflex was present in $60 \%$ of the cases.

In the present study of craniovertebral junction anomaly, $12(60 \%)$ males and 8 (40\%) female patients were operated in our institution. It included congenital, ${ }^{3}$ traumatic, ${ }^{14}$ and RA. ${ }^{3}$ Out of the 20 patients, $4(20 \%)$ were smoker and 1 patient was having scoliosis. All the 20 patients had undergone preoperative PFT.

All the patients were extubated within 96 hours of operation. Postoperative pulmonary functions were obtained on seventh postoperative day in all 20 patients. In the preoperative period all the measured pulmonary functions were significantly lower than the predicted normal values ( - Table1). The mean values of FVC, FEV1, FEF25-75\% were 72 , 68, and 71\% of their mean predicted values. The FEV1\% was within the range of 70 to $95 \%$ with the mean of $81.4 \%$.
Postoperatively (after 7 days) there was further significant reduction in the mean values of FVC, FEV1, and FEF25-75\% compared with the preoperative values ( $\bullet$ Fig. 1).

The mean FEV1\% was also reduced significantly. The comparison of values in pre and postoperative period has been depicted in - Table 2. Seven (35\%) patients were in McCormick grade II neurological deficit, while ten (50\%) and three (15\%) were in McCormick grades III and IV, respectively. In postoperative period $5(25 \%)$ patients had McCormick grade I, 11 (55\%) had McCormick grade II, and 2 (10\%) each had McCormick grades III and IV. Out of three (15\%) of the McCormick grade IV patients, two (10\%) patients improved to grade III while one (5\%) patient was not improved neurologically and stayed as grade IV. Out of the ten (50\%) patients of preoperative grade III status, eight patients (40\%) were improved neurologically to grade II, and one (5\%) patient was improved to grade I, while one $(5 \%)$ patient deteriorated neurologically to grade IV. Out of the seven (35\%) of the McCormick grade II patients, four (20\%) patients improved to grade I, while three (15\%) patients remained in grade II.

\section{Discussion}

In the present study of craniovertebral junction anomaly, $60 \%$ males and $40 \%$ female patients were operated. Twenty patients with craniovertebral junction anomaly were studied with PFT preoperatively and on the seventh postoperative day. The mean values of FVC, FEV1, and FEF25-75\% were 72,68 and $71 \%$ of their normal predicted values, respectively, which were significantly less ( $p$-value $<0.001$ ). The mean FEV1\% was within normal range being $81.4 \%$. This signifies that these patients had a mixed obstructive and restrictive pattern of respiratory disease. In the early postoperative period, there was a significant decrease $(p$-value $<0.001)$ in all mean respiratory parameters compared with preoperative values; though the mean FEV1\% also decreased significantly (72.8 vs. 81.4 ) it was within normal limit. This implies that even with the reduction of ratio the restrictive pattern of respiration persisted in the postoperative period. The reduction in the respiratory parameters may be attributed to residual edema after surgical manipulations. Pain at the operated site needs considerations. As the restrictive pattern continued during the postoperative period the possibility of atelectasis may have also developed. Rosomoff has described the reduced vital capacity, maximum breathing capacity, and lung compliance, despite the absence of clinical evidence of pulmonary diseases in patients of CVJ anomalies. ${ }^{24}$ In one

Table 1 Preoperative pulmonary function test

\begin{tabular}{|l|l|l|l|}
\hline & Predicted (mean \pm SD) & Observed (mean \pm SD) & $p$-Value \\
\hline FVC & $3.27 \pm 0.46$ & $2.39 \pm 0.45$ & $<0.00001$ \\
\hline FEV1 & $2.89 \pm 0.43$ & $1.94 \pm 0.38$ & $<0.00001$ \\
\hline FEV1\% & $88.01 \pm 2.14$ & $81.47 \pm 6.62$ & $<0.0002$ \\
\hline FEF25-75\% & $3.18 \pm 0.52$ & $2.27 \pm 0.48$ & $<0.00001$ \\
\hline
\end{tabular}

Abbreviations: FEF, forced expiratory flow; FEV1, forced expiratory volume in one second; FVC, forced vital capacity; SD, standard deviation. 


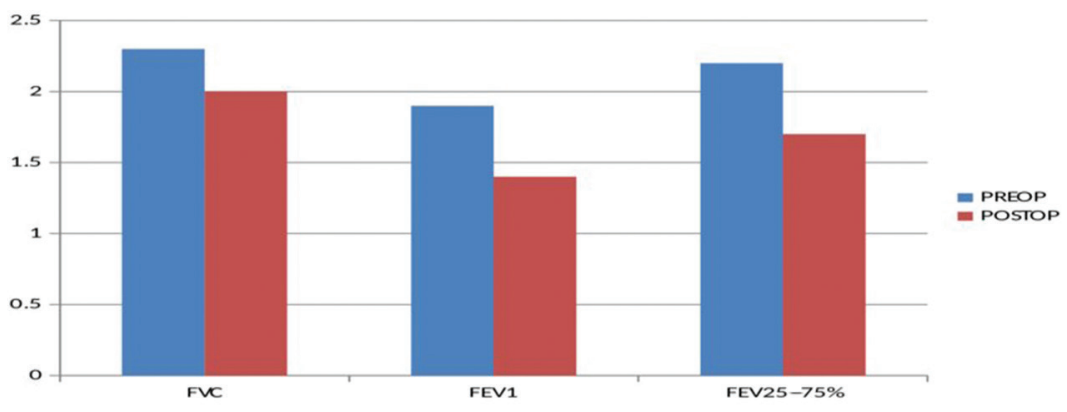

Fig. 1 Comparison of pulmonary function test in pre- and postoperative period. Abbreviations: FVC, forced vital capacit; FEV1, forced expiratory volume in one second; FEF25-75\%, maximum forced mid-expiratory flow rate; POSTOP, Postoperative; PREOP, Preoperative.

Table 2 Preoperative and postoperative pulmonary function test

\begin{tabular}{|l|l|l|l|}
\hline & Preoperative (Mean \pm SD) & Postoperative (Mean \pm SD) & $p$-Value \\
\hline FVC & $2.39 \pm 0.45$ & $2.03 \pm 0.57$ & 0.02 \\
\hline FEV1 & $1.94 \pm 0.38$ & $1.48 \pm 0.45$ & 0.001 \\
\hline FEV1\% & $81.47 \pm 6.62$ & $72.88 \pm 10.35$ & 0.001 \\
\hline FEF25-75\% & $2.27 \pm 0.48$ & $1.74 \pm 0.44$ & 0.00001 \\
\hline
\end{tabular}

Abbreviations: FEF, forced expiratory flow; FEV1, forced expiratory volume in one second; FVC, forced vital capacity; SD, standard deviation.

Indian study a restrictive pattern was observed which persisted in the postoperative period. ${ }^{25}$ These findings were similar to those found in our study. It therefore forewarns that the care of chest and respiratory parameters in postoperative period is of paramount importance. The improvement may not occur in initial 7 to 10 days and hence it is mandatory to observe these cases even more carefully and very judiciously. We, however, did not repeat PFT in these cases as most of them belonged to different states and remote areas and hence they were not available for objective PFT analysis after discharge.

\section{Conclusion}

Present study showed that a significant restrictive lung disease is present in patients of craniovertebral junction anomaly, even though it is not apparent clinically. In the first 7 days PFT may even go down because of multiple factors like pain and neurological deterioration. These patients are at high risk of pulmonary complication so vigorous chest physiotherapy should be done. Smoking and congenital chest anomaly are also contributing factors in poor PFT. The clinically insignificant restrictive pulmonary dysfunctions persist in the early postoperative period. However, a long-term follow-up is required to assess whether these parameters improve subsequently. There is restrictive pattern of pulmonary function in early postoperative period; it warrants the need for careful monitoring for acute respiratory event in this period and hence, one should not be in a hurry for early extubation and discharge of these patients.

\section{Conflict of Interest}

None declared.

\section{References}

1 Vender JR, Rekito AJ, Harrison SJ, McDonnell DE. The evolution of posterior cervical and occipitocervical fusion and instrumentation. Neurosurg Focus 2004;16(1):E9

2 Crockard HA, Stevens JM. Craniovertebral junction anomalies in inherited disorders: part of the syndrome or caused by the disorder.? Eur J Pediatr 1995;154(7):504-512

3 Crockard HA. Transoral surgery: some lessons learned. $\mathrm{Br} \mathrm{J}$ Neurosurg 1995;9(3):283-293

4 Erbengi A, Oge HK. Congenital malformations oh the craniovertebral junction: classification and surgical treatment. Acta Neurochir (Wien) 1994;127:180-185

5 Menezes AH, Ryken TC. Craniovertebral abnormalities in Down's syndrome. Pediatr Neurosurg 1992;18(1):24-33

6 Menezes AH, VanGilder AC. Abnormalities of the Craniovertebral Junction. In: Youmans J, Becker P, Dunker S, eds. Neurological Surgery. 3rd ed. Philadelphia PA: Saunders;1990:1350-1420

7 VanGilder JC, Menezes AH. Craniovertebral Abnormalities and Their Treatment. In: Schmidek HH, Sweet WH, eds. Operative Neurosurgical Techniques. New York, NY: Grune and Stratton; 1982:1221-1235

8 VanGilder JC, Menezes AH. Craniovertebral Junction Abnormalities. In: Wilkins RH, Rengachary SS, eds. Neurosurgery, Vol 3. New York, NY: McGraw-Hill;1985:2097- 2101

9 Garrido BJ, Myo GK, Sasso RC. Rigid versus nonrigid occipitocervical fusion: a clinical comparison of short-term outcomes. J Spinal Disord Tech 2011;24(1):20-23

10 Vaiman M, Beckerman I. Importance of preoperative detection of vertebral artery anomalies in neck surgery. ANZ J Surg 2011;81(3):164-167

11 Yeom JS, Buchowski JM, Park KW, Chang BS, Lee CK, Riew KD. Undetected vertebral artery groove and foramen violations during $\mathrm{C} 1$ lateral mass and $\mathrm{C} 2$ pedicle screw placement. Spine 2008;33(25):E942-E949

12 VanGilder JC, Menezes AH. Craniovertebral abnormalities: symptoms, etiology and treatment. Contemp Neurosurg 1981; $3: 1-6$

13 Fehlings MG, Errico T, Cooper P, Benjamin V, DiBartolo T. Occipitocervical fusion with a five-millimeter malleable rod 
and segmental fixation. Neurosurgery 1993;32(2):198-207, discussion 207-208

14 Lu DC, Roeser AC, Mummaneni VP, Mummaneni PV. Nuances of occipitocervical fixation. Neurosurgery 2010;66(suppl 3): 141-146

15 Nishikawa M, Ohata K, Baba M, Terakawa Y, Hara M. Chiari I malformation associated with ventral compression and instability: one-stage posterior decompression and fusion with a new instrumentation technique. Neurosurgery 2004;54(6): 1430-1434, discussion 1434-1435

16 Milhorat TH, Chou MW, Trinidad EM, et al. Chiari I malformation redefined: clinical and radiographic findings for 364 symptomatic patients. Neurosurgery 1999;44(5):1005-1017

17 Smith JS, Shaffrey CI, Abel MF, Menezes AH. Basilar invagination. Neurosurgery 2010;66(suppl 3) :39-47

18 Jain VK, Mittal P, Banerji D, Behari S, Acharya R, Chhabra DK. Posterior occipitoaxial fusion for atlantoaxial dislocation associated with occipitalized atlas. J Neurosurg 1996;84(4): 559-564

19 McCormick PC, Torres R, Post KD, Stein BM. Intramedullary ependymoma of the spinal cord. J Neurosurg 1990;72(4): 523-532
20 Yu X, Li L, Wang P, Yin Y, Bu B, Zhou D. Intraoperative computed tomography with an integrated navigation system in stabilization surgery for complex craniovertebral junction malformation. J Spinal Disord Tech 2014;27(5):245-252

21 Zausinger S, Scheder B, Uhl E, Heigl T, Morhard D, Tonn JC. Intraoperative computed tomography with integrated navigation system in spinal stabilizations. Spine 2009;34(26): 2919-2926

22 Tian NF, Xu HZ. Image-guided pedicle screw insertion accuracy: a meta-analysis. Int Orthop 2009;33(4):895-903

23 Chen L-f, Yang YYUX-gBUBXUB-nZhouD-b. Revision surgery after inappropriate posterior fossa decompression for craniocervical junction malformation [in Turkish]. Neurol Sci Physiol 2013;30:515:524

24 Rosomoff HL. Occult respiratory and autonomic dysfunction in craniovertebral anomalies and upper cervical spinal disease. Spine 1986;11(4):345-347

25 Rath GP, Bithal PK, Guleria R, et al. A comparative study between preoperative and postoperative pulmonary functions and diaphragmatic movements in congenital craniovertebral junction anomalies. J Neurosurg Anesthesiol 2006;18(4):256-261 